\title{
Experiencia de creación e dinamización do MOOC Tecnoloxías para a Participación Activa na Diversidade Funcional
}

\author{
Pousada García, Thais ${ }^{1 ;}$ N Nieto-Riveiro, Laura²; Groba González, Betania33; Pereira \\ Loureiro, Javier $^{4}$
}
1, 2, 3, ${ }^{4}$ Centro de Investigación en Tecnoloxías da Información e as Comunicacións (CITIC), Grupo TALIONIS, Facultade de Ciencias da Saúde, Universidade da Coruña, ${ }^{1} 0000-0003-3356-0429$
${ }^{2} 0000-0003-3460-5895$
${ }^{3} 0000-0001-5547-2337$
${ }^{4} 0000-0001-9328-0723$

\section{RESUMO}

Neste capítulo, preséntase a experiencia de creación e dinamización do MOOC "Tecnoloxías para a Participación Activa na Diversidade Funcional", impartido a través de Miríadax entre Xaneiro e Febreiro de 2019, e orientado á transferencia de coñecemento á sociedade sobre as potencialidades ofrecidas pola tecnoloxía para facilitar a participación e a autonomía das persoas con diversidade funcional. 0 curso estruturouse en catro módulos centrais, conformados por textos, vídeos, test de autoavaliación e outros materiais complementarios con información de referencia sobre a temática. Para a dinamización do curso, empregáronse: correos masivos, foro, retos semanais e comunidade en Google+. Os resultados superaron as expectativas iniciais do equipo docente, acadando cotas elevadas de participación e satisfacción entre 0 alumnado, e finalizando con éxito a formación máis de 250 persoas. Destacou especialmente a participación voluntaria nos retos semanais e na comunidade de Google+, na que se publicaron máis de 80 materiais orixinais elaborados polo alumnado. Así, nesta primeira experiencia púidose cumprir co obxectivo de transferencia de coñecemento á sociedade, e facelo a través dunha ferramenta gratuíta e interactiva. Os resultados obtidos permiten concluír que tanto os contidos abordados como as metodoloxías e materiais empregados, foron axeitados para favorecer a aprendizaxe e a motivación do alumnado.

PALABRAS CHAVE: diversidade, MOOC, participación, tecnoloxía, transferencia. 


\section{CITA RECOMENDADA:}

Pousada García, Thais; Nieto-Riveiro, Laura; Groba González, Betania; Pereira Loureiro, Javier (2020): Experiencia de creación e dinamización do MOOC Tecnoloxías para a Participación Activa na Diversidade Funcional. En De la Torre Fernández, E. (ed.) (2020). Contextos universitarios transformadores: Boas prácticas no marco dos GID. IV Xornadas de Innovación Docente. Cufie. Universidade da Coruña. A Coruña (págs. 177-190).

DOl capítulo: https://doi.org/10.17979/spudc. 9788497497756.177

DOl libro: https://doi.org/10.17979/spudc.9788497497756

\section{ABSTRACT}

This chapter presents the experience of creation and dynamization of the MOOC "Technologies for Active Participation in Functional Diversity", developed through Miríadax between January and February 2019, and oriented to the transfer of knowledge to society about the potentialities offered by technology to facilitate the participation and autonomy of people with functional diversity. The course was structured in four central modules, made up of texts, videos, self-assessment tests and other complementary materials with reference information on the subject. For the dynamization of the course, the following were used: mass mailings, forum, weekly challenges and community on Google+. The results exceeded the initial expectations of the teaching team, achieving high levels of participation and satisfaction among the students; more than 250 people successfully completed the training. The voluntary participation in the weekly challenges and in the Google + community was particularly noteworthy, with more than 80 publications with original materials produced by the students. Thus, in this first experience it was possible to meet the objective of transferring knowledge to society, through a free and interactive tool. The results obtained allow concluding that both the contents approached and the methodologies and materials used were adequate to promote learning and motivation of students.

KEY WORDS: diversity, MOOC, participation, technology, transfer. 


\section{INTRODUCCIÓN}

A orixe da presente proposta atópase na I Convocatoria para a elaboración de M00Cs da Universidade da Coruña (UDC), que foi publicada pola Vicerreitoría de Oferta Académica e Innovación Docente en Febreiro de 2018.

Os MOOCs (Massive Open Online Courses) son cursos abertos en liña, que se caracterizan pola súa gratuidade, masividade e ubicuidade.

Tras unha revisión exhaustiva de distintas plataformas destinadas á realización deste tipo de cursos, detectouse a ausencia dun MOOC centrado na difusión de coñecementos sobre recursos tecnolóxicos de apoio para as persoas con diversidade funcional.

Por iso, ao abeiro da mencionada convocatoria, as/os autoras/es desta comunicación propuxeron a realización dun MOOC titulado "Tecnoloxías para a Participación Activa na Diversidade Funcional".

Esta proposta baseouse na experiencia previa coa que contaban as/os autoras/es no campo da docencia e a investigación sobre a temática central do curso, e na difusión de contidos formativos en diferentes modalidades. Neste sentido, foi tamén un impulso para presentar esta proposta, a participación do equipo de traballo, xunto a outras/os profesoras/es, nun Grupo de Innovación Docente da UDC, chamado "Gamificación e interactividade nas aulas", consolidado en Novembro de 2017.

Unha vez foi admitida a proposta, as/os autoras/es xeraron os contidos e actividades necesarias para a implementación do curso, e coordinaron e dinamizaron o seu desenvolvemento.

0 obxectivo deste MOOC focalizouse na transferencia de coñecemento libre, aberto e accesible á sociedade sobre as potencialidades que ofrece a tecnoloxía para facilitar a participación activa e a autonomía das persoas con diversidade funcional. Así, co desenvolvemento deste MOOC pretendíase ofrecer unha perspectiva práctica e completa sobre as principais características, o funcionamento e a aplicabilidade de diferentes recursos tecnolóxicos e produtos de apoio (hardware e software para ordenador, APPs, realidade 
virtual, robótica, software de programación, etc.), que poden ter un impacto substancial no promoción da autonomía e a participación das persoas con diversidade funcional.

\section{DESCRICIÓN DA EXPERIENCIA}

Este MOOC desenvolveuse na plataforma Miríadax de Xaneiro a Febreiro de 2019, durante un período total de cinco semanas (ver Figura 1Figura 1).

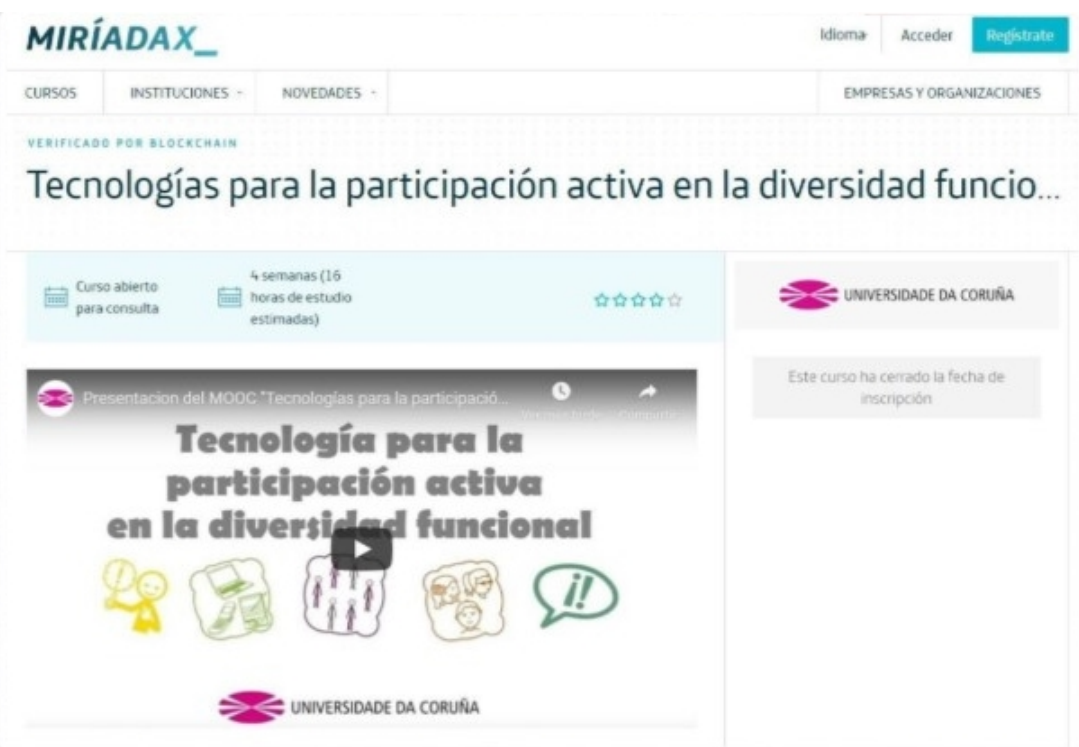

Figura 1. Pantalla inicial do curso en Miríadax

0 curso estruturouse en catro módulos centrais (ver Figura 2): (1) Produtos e tecnoloxías de apoio-Xeneralidades, (2) Ferramentas para a participación virtual, (3) Software de programación fácil Parte I-Scratch e (4) Parte II-Makey Makey. Incorporáronse, ademais, dous módulos complementarios, un inicial, de presentación, e outro final, para o peche do curso. 


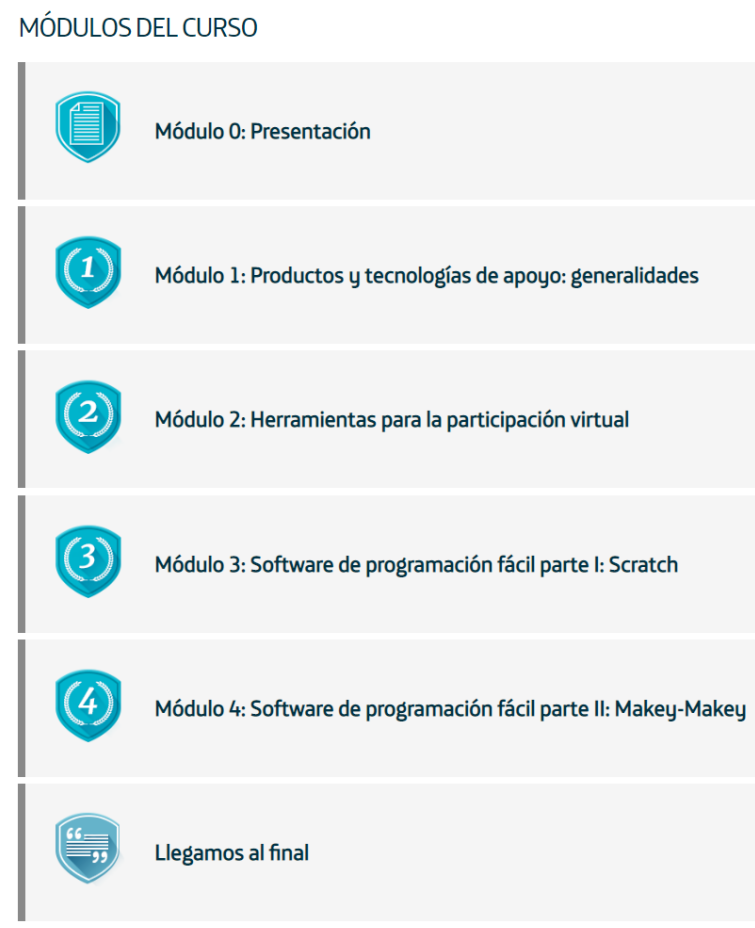

Figura 2. Estrutura en módulos do curso

No módulo de presentación, incluíuse unha enquisa inicial, encamiñada a obter unha información máis detallada das persoas participantes no MOOC, e coñecer as súas expectativas e motivacións para realizar o curso. No módulo de peche, incorporouse unha enquisa final, destinada a recoller as impresións do alumnado sobre o curso (contidos, metodoloxías, etc.) e os resultados acadados. Ambas enquisas foron elaboradas polo equipo docente, en base aos modelos de cuestionario inicial e final empregados no MOOC "Música para 0 s. XXl". Foron creadas coa aplicación Microsoft Forms (do paquete Office 365), e vinculadas coa plataforma Miríadax a través dun enlace externo.

Cada un dos catro módulos centrais tivo unha duración dunha semana, prolongándose 0 curso unha semana adicional (en total, cinco semanas) para ofrecer tempo suficiente para que 0 alumnado completase a lectura e visualización de todos os contidos presentados, e a realización das tarefas requiridas. 
Para cada módulo, estimouse unha dedicación por estudante de 4 horas por semana (en total, 16 horas), destinadas á consulta dos materiais formativos básicos, a realización das actividades propostas e a participación no foro.

Cada módulo estivo conformado por información de referencia sobre a súa temática central, empregando textos, vídeos e outros materiais complementarios, de elaboración propia, para a exposición da devandita información. Ofreceuse a posibilidade de descargar a documentación complementaria, para que as/os participantes puidesen consultalos posteriormente, unha vez finalizase a formación.

Ademais, preparouse un test de autoavaliación para cada módulo (obrigatorios para a superación do curso), co fin de que as persoas participantes puidesen valorar autonomamente, e de forma práctica e dinámica, o seu progreso no curso.

Para a dinamización da participación do alumnado no curso, fíxose uso de diferentes estratexias:

- Envío de correos masivos a través de Miríadax, para informar sobre a apertura do curso e de cada un dos seus módulos, e recordar os prazos de participación. Ao longo de todo 0 curso, enviáronse un total de 10 e-mails a través desta modalidade.

- Uso do foro desta mesma plataforma, que permitiu, ademais de transmitir a información recollida no punto anterior, resolver as dúbidas que presentasen as persoas participantes e facilitar que compartisen experiencias e coñecementos en torno ás temáticas traballadas no curso.

- Proposta de retos semanais, de carácter voluntario, vinculados aos contidos abordados en cada módulo.

- Creación e xestión dunha comunidade en Google+, na que 0 alumnado tiña a posibilidade de compartir os materiais e actividades elaborados como parte dos retos semanais.

Cada módulo foi coordinado e impartido por unha ou dúas persoas integrantes do equipo docente, en función da súa especialización. Todas/os as/os docentes participaron activamente 
na dinamización do foro e a comunidade en Google+, na revisión dos materiais e actividades elaborados polo alumnado como parte dos retos semanais, e no seguimento xeral da evolución do curso. Aínda así, asignouse de forma específica a cada integrante a titorización dunha semana do curso, en función da coordinación establecida para cada módulo, de cara a realizar unha titorización especializada da participación no curso.

Como xa se mencionou ao principio deste apartado, este MOOC impartiuse en Miríadax entre Xaneiro e Febreiro de 2019. 0 procedemento que se levou a cabo de forma previa foi 0 seguinte:

- De Febreiro a Marzo de 2018: Preparación da solicitude para a convocatoria publicada pola UDC.

- De Abril a Xuño de 2018: Planificación detallada dos roles do equipo docente e dos contidos do curso.

- De Xuño a Xullo de 2018: Gravación dos vídeos correspondentes aos módulos 1, 2, 3 e 4 .

- De Setembro a Outubro de 2018: Gravación do vídeo de presentación e revisión dos vídeos gravados nos meses anteriores.

- De Novembro a Decembro de 2018: Configuración do material na plataforma de Miríadax, e revisión e aprobación final do MOOC.

Ao longo de todo o proceso, o equipo docente contou co apoio e 0 asesoramento tanto do Centro Universitario de Formación e Innovación Educativa (CUFIE) da UDC (sendo a coordinadora do curso Ana Peña Cabanas, da Unidade de Teleformación do CUFIE) como do persoal técnico da plataforma Miríadax. Este apoio resultou fundamental, xa que, aínda que as/os autoras/es presentaban experiencia na docencia e investigación sobre a temática central do curso e na difusión de contidos formativos en diferentes modalidades, non contaban con experiencia previa na realización de M00Cs. 


\section{RESULTADOS}

Os resultados obtidos superaron as expectativas iniciais do equipo docente. 0 número total de persoas inscritas foi de 862, completando todos os módulos e finalizando o curso 254 persoas. Na seguinte táboa (ver Táboa 1), recóllense os números de participación total e de participación por cada módulo.

\begin{tabular}{|l|c|c|}
\hline$N^{0}$ total de persoas inscritas & \multicolumn{2}{|c|}{$\mathbf{8 6 2}$} \\
\hline$N^{0}$ de persoas que comezaron o curso & & 593 \\
\hline $\begin{array}{l}N^{0} \text { de persoas que finalizaron o curso (completando todos os } \\
\text { módulos, incluído o final) }\end{array}$ & $\mathbf{2 5 4}$ \\
\hline Módulo & $\mathbf{N}^{0}$ inicio & $\mathbf{N}^{\mathbf{0}}$ finalización \\
\hline Módulo 0: Presentación & 548 & 538 \\
\hline Módulo 1: Produtos e tecnoloxías de apoio-Xeneralidades & 559 & 366 \\
\hline Módulo 2: Ferramentas para a participación virtual & 421 & 292 \\
\hline Módulo 3: Software de programación fácil parte I-Scratch & 354 & 284 \\
\hline Módulo 4: Software de programación fácil parte II-Makey-Makey & 314 & 278 \\
\hline Módulo final (enquisa) & 261 & 258 \\
\hline
\end{tabular}

Táboa 1. Datos sobre inscrición e finalización do curso, globais e por cada módulo

0 perfil tipo de participante neste MOOC é o dunha muller de entre 25 e 34 anos, que finalizou os seus estudos universitarios e de nacionalidade española. Non obstante, os países de orixe das persoas participantes foron moi diversos, recolléndose diferentes nacionalidades de Centro América, América do Sur, América do Norte, Europa, Asia e África, como por exemplo, Estados Unidos, Corea do Sur ou Angola.

Na enquisa inicial (cuberta por 25 persoas), a maioría de participantes expresaron que non tiñan participado anteriormente en ningún MOOC (64\%), e que tampouco tiñan experiencia previa no campo da tecnoloxía de apoio para as persoas con diversidade funcional (68\%).

Nesta enquisa, indicaron tamén os seus principais intereses para a participación neste curso (ver Figura 3), destacando o interese por ampliar os seus coñecementos (92\%), a gratuidade da formación (56\%) e o interese científico da temática (52\%). 
14. ¿Por qué te interesa hacer este curso? Selecciona tantas como corresponda
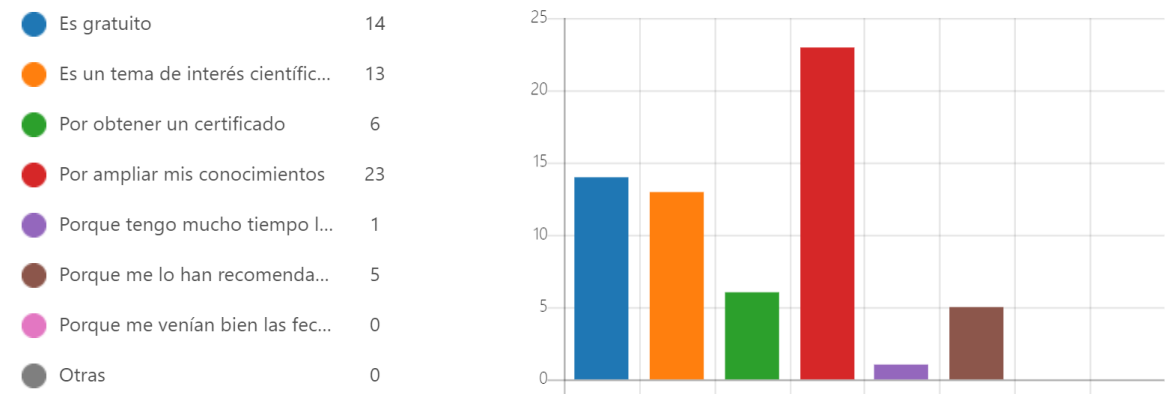

Figura 3. Respostas do alumnado participante na Enquisa inicial, sobre Intereses en torno ao curso

En xeral, a participación no curso foi moi positiva. Destacou especialmente a participación voluntaria na comunidade de Google+, que implicaba interaccións virtuais simples e outras que esixían un esforzo adicional (elaboración dunha presentación con pictogramas, dunha infografía e de contidos multimedia con Scratch). As estatísticas da última semana do curso amosan un elevado número de comentarios (115) e reaccións positivas (170) ás publicacións da comunidade. Tamén cabe salientar que houbo máis de 80 publicacións de materiais orixinais do alumnado.

Así mesmo, rexistrouse unha participación satisfactoria no foro oficial do curso, dispoñible na plataforma de Miríadax, o cal foi empregado como ferramenta principal de comunicación entre 0 equipo docente e 0 alumnado, fundamentalmente para aclarar as dúbidas existentes sobre os contidos do curso ou sobre o seu desenvolvemento técnico. En concreto, contabilizáronse un total de 19 discusións e 81 mensaxes.

Con respecto á satisfacción do alumnado co curso, cabe salientar que cumprimentaron a enquisa final 70 persoas. Nos datos recollidos nesta enquisa, pódese apreciar un interese elevado da maioría de participantes polos catro módulos desenvoltos (entre un 62 e un 70\% do alumnado, segundo o módulo, escolleron a opción "moito" interese), tal e como se amosa na Figura 4. 
1. Puntúa el interés que le haya suscitado cada módulo del curso, donde 1 es nada y 4 es mucho.

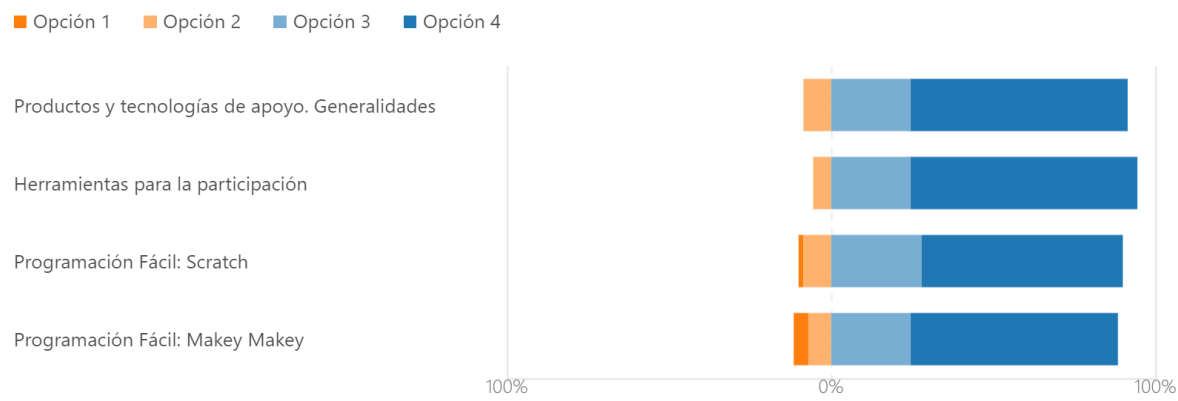

Figura 4. Respostas do alumnado participante na Enquisa final, sobre Interese por cada módulo

Tamén se pode observar unha satisfacción maioritaria con diferentes aspectos do curso, como as propostas de retos semanais, o ritmo de aprendizaxe, a duración dos vídeos ou os documentos teóricos, tal e como indicaron un $83 \%$, un $84 \%$, un $93 \%$ e un $99 \%$ de persoas, respectivamente (ver Figura 5, Figura 6, Figura 7 e Figura 8).

3. ¿Te han gustado las propuestas de retos semanales?

Sí, me han encantado y he parti... 9

Sí, aunque no he podido partici... 49

No he accedido a la Comunidad... 7

Los retos semanales me han par... 5

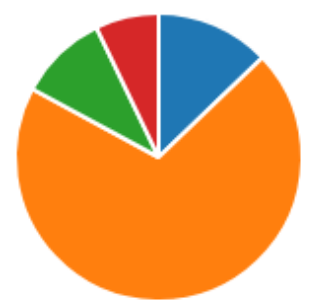

Figura 5. Respostas do alumnado participante na Enquisa final, sobre os Retos semanais 
8. El ritmo de aprendizaje del curso le ha resultado:

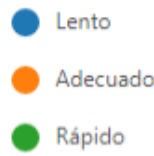

5
57
6

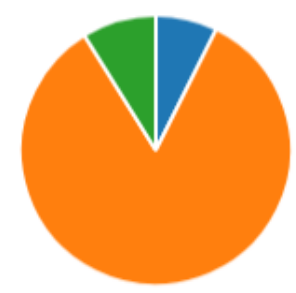

Figura 6. Respostas do alumnado participante na Enquisa final, sobre o Ritmo de aprendizaxe

9. Considera que la duración de los vídeos es:

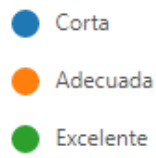

5
62
3

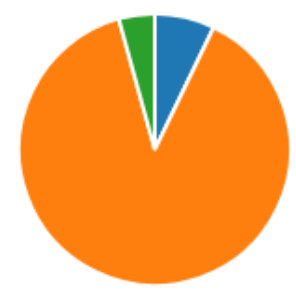

Figura 7. Respostas do alumnado participante na Enquisa final, sobre a Duración dos vídeos

10. Considera que las documentos teóricos son:
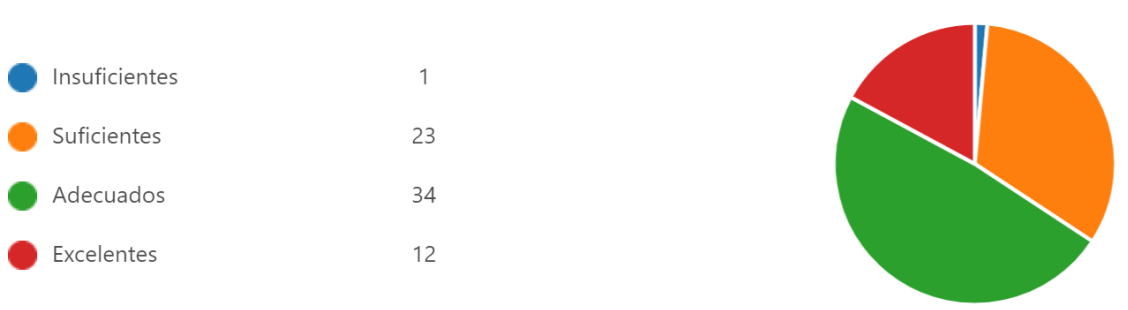

Figura 8. Respostas do alumnado participante na Enquisa final, sobre a Documentación teórica

En concreto, as persoas participantes na enquisa final indicaron que as ferramentas que facilitaron en maior medida a súa aprendizaxe durante o curso (ver Figura 9) foron: os contidos en formato de vídeo (87\%), a documentación de apoio ou complementaria (71\%), os test ou cuestionarios de autoavaliación (34\%), os enlaces externos (33\%) e os retos semanais (32\%). 
4. ¿Qué herramientas consideras que han facilitado más tu aprendizaje en el curso? Selecciona tantas como se correspondan
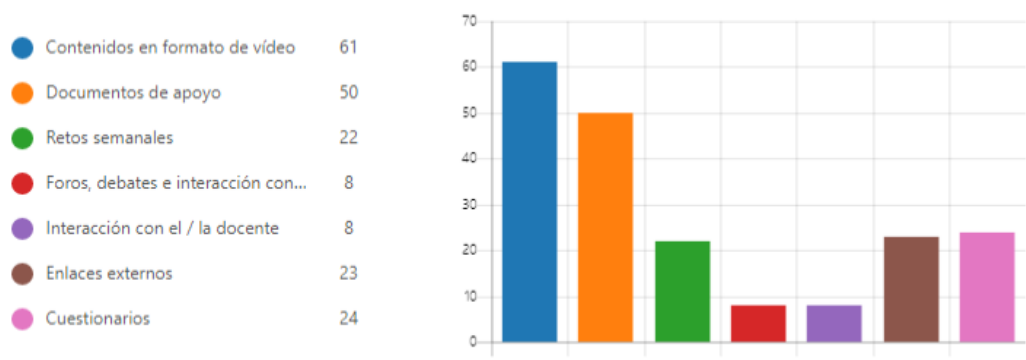

Figura 9. Respostas do alumnado participante na Enquisa final, sobre as Ferramentas do curso

Ademais, todo o alumnado que respondeu á enquisa final, manifestou ter aprendido, en maior ou menor medida, coa participación no MOOC, acadando unha puntuación media de 4,26 sobre 5 en relación ao cumprimento do curso coas súas expectativas iniciais (ver Figura 10).

12. Su apreciación general del curso es:
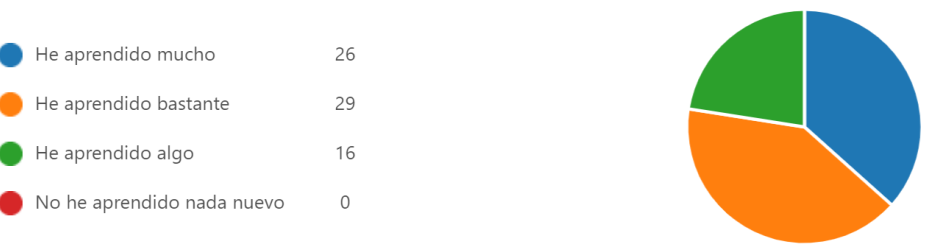

13. Valore si con este curso se han cumplido sus expectativas, siendo 1 la menor puntuación y 5 la mayor.

70

Respuestas
4.26

Promedio

Figura 10. Respostas do alumnado participante na Enquisa final, sobre Aprendizaxe durante o curso e cumprimento de Expectativas

Finalmente, outro dos resultados destacables foi a elaboración e publicación de dous documentos recompilatorios coa información completa do curso: "Produtos e tecnoloxías de apoio" (Groba, Nieto-Riveiro \& Pereira, 2019) e "Ferramentas para a participación, 
intervención e aprendizaxe virtual" (Pousada, 2019). Ambos documentos contan con cifras elevadas de visualizacións, 1.494 e 928 respectivamente (consultadas en Xaneiro de 2020), procedentes na súa maioría de España, pero tamén doutros países como Arxentina, Ecuador, Chile, México, Perú, Estados Unidos, Reino Unido ou Alemaña.

\section{CONCLUSIÓNS}

Aínda que xurdiron dificultades no desenvolvemento do MOOC, esta primeira experiencia permitiu cumprir co obxectivo de transferencia do coñecemento á sociedade e facelo a través dunha ferramenta gratuíta e interactiva.

Os resultados obtidos permiten concluír que coa realización deste tipo de cursos pódense acadar niveis elevados de participación e implicación por parte do alumnado, considerándose adecuados para a súa formación tanto os ritmos de aprendizaxe establecidos como os distintos formatos de materiais e metodoloxías implementadas nesta ocasión (vídeos, documentación teórica, test de autoavaliación, proposta de retos semanais, etc.).

Os contidos abordados no MOOC "Tecnoloxías para a Participación Activa na Diversidade Funcional" tamén resultaron de gran interese para as persoas participantes, recolléndose unha satisfacción maioritaria cos mesmos. Por isto, pódese concluír, ademais, que é importante incorporar estas temáticas ou outras similares en futuras accións formativas, xa que existe demanda e motivación cara as mesmas por parte da comunidade usuaria deste tipo de plataformas educativas.

\section{AGRADECEMENTOS}

Para 0 desenvolvemento desta experiencia, agradécese 0 apoio recibido por parte da Vicerreitoría de Oferta Académica e Innovación Docente da UDC, do CITIC (Centro de Investigación Singular do Sistema Universitario de Galicia, financiado pola Consellería de Educación, Universidade e Formación Profesional da Xunta de Galicia, a través do Fondo Europeo de Desenvolvemento Rexional, no marco do Programa Operativo FEDER Galicia 2014- 
2020, e a Secretaría Xeral de Universidades, Ref. ED431G 2019/01), do persoal técnico da plataforma Miríadax e, especialmente, do CUFIE da UDC. Neste sentido, agradécese, en particular, a colaboración de Ana Peña Cabanas, da Unidade de Teleformación do CUFIE, quen se encargou da coordinación xeral do curso e de resolver todas as dúbidas que lle xurdiron ao equipo docente ao longo de todo o proceso.

\section{REFERENCIAS}

Groba, B., Nieto-Riveiro, L. \& Pereira, J. (2019). Produtos e tecnoloxías de apoio: xeneralidades. A Coruña: Servizo de Publicacións, Universidade da Coruña. Dispoñible en http://hdl.handle.net/2183/21548

Pousada, T. (2019). Ferramentas para a participación, intervención e aprendizaxe virtual. A Coruña: Servizo de Publicacións, Universidade da Coruña. Dispoñible en http://hdl.handle.net/2183/21445 